\title{
TEMPERATURE TOLERANCE AND OTHER PROPERTIES OF TWO ETHANOL PRODUCING SACCHAROMYCES CEREVISIAE STRAINS ISOLATED FROM COCONUT TODDY
}

\author{
S. CHANDRANI WIJEYARATNE \\ Department of Botany, University of Sri Jayewardenepura, Nugegoda.
}

(Received: 06th February 1997; accepted: 03 April 1998)

\begin{abstract}
Several yeast strains capable of fermenting glucose at $40^{\circ} \mathrm{C}$ were isolated from coconut toddy. Two strains, which gave high ethanol concentration at $40^{\circ} \mathrm{C}$ were identified as strains of Saccharomyces cerevisiae. Strain T-31 (NCYC 2401) at $40^{\circ} \mathrm{C}$ gave high alcohol concentration in both YPS and molasses media, $7.4 \%$ and $5.4 \%$ v/v respectively, while strain SK-33 (NCYC 2402) gave higher concentration of alcohol in synthetic medium, $8.4 \% \mathrm{v} / \mathrm{v}$. The maximum growth temperature of both these strains was $45^{\circ} \mathrm{C}$ indicating their thermotolerant behaviour. Of these two strains, T-31 was found to be suitable for alcohol fermentation at high temperature $\left(40^{\circ} \mathrm{C}\right)$ using molasses, based on parameters such as maximum $\mathrm{CO}_{2}$ productivity $\left(0.216 \mathrm{gh}^{-1}\right)$, final ethanol concentration $(7.4 \% \mathrm{v} / \mathrm{v})$, yield efficiency $(0.579)$ and minimal cell growth rate $\left(0.029\right.$ cells $^{-1}$ $\left.\mathrm{h}^{-1}\right)$.
\end{abstract}

Key Words: Coconut sap, coconut toddy, ethanol, Saccharomyces cerevisiae, temperature tolerance, yeast.

\section{INTRODUCTION}

The limited availability of world's crude oil and its constant price increase aroused renewed interest in the gasohol concept. Fuel ethanol has been produced in Brazil since 1933, while both Germany and Japan used it as a source of fuel during the Second World War. Production of fuel ethanol using industrial byproducts such as molasses would be a promising endeavour for developing countries, which do not have any fossil fuels.

Molasses, which is a by-product of cane sugar industry, is mainly utilised in the production of ethanol in the distilleries of Sri Lanka. With the setting up of new sugar factories in the country, there is a considerable increase in the availability of sugarcane molasses. Nevertheless, these distilleries operate at low efficiencies $(50-60 \%)$ compared to other distilleries in the world. ${ }^{1}$ This is due to inefficiency in the method of distillation and unsuitability of the yeast strains for fermenting molasses under tropical environmental conditions. The compound effect of high ambient temperature in tropical countries and exothermic fermentation reaction elevate the temperature of the fermentation mash. High temperature usually inhibits the fermentation ability of the yeast strain used, as most of the conventional yeasts are temperature sensitive. To minimise this inhibition, a cooling system is used to maintain the temperature around $35^{\circ} \mathrm{C}$ or 
below. However this process increases the capital and running costs. In view of this situation, tropical fermentation technology as regards ethanol fermentation by yeast, requires strains capable of fermenting sugars efficiently at high temperature of around $40^{\circ} \mathrm{C}$. There are certain advantages in high temperature fermentation by yeast. They are, faster rates of substrate consumption and ethanol formation, facilitation of easy ethanol recovery and savings on cooling cost. As the fermentation is completed within $36-48 \mathrm{~h}$, loss of ethanol due to evaporation is considerably less even at temperatures around $40^{\prime \prime} \mathrm{C}$. Therefore, use of high temperature tolerant yeast, in fermentation industry under tropical environmental conditions is cost effective. There are several reports on the isolation of thermotolerant strains belonging to different genera. The isolation of five thermotolerant strains of Kluyveromyces strains capable of growth and high-level ethanol production, on glucose and molasses fermentation, at temperatures in the range of $45-50^{\circ} \mathrm{C}$ had been reported. Kluyveromyces marxianus IMB 3 had produced $35 \mathrm{~g} / \mathrm{l}$ of alcohol at $13 \mathrm{~h}$ following growth at $45^{\prime \prime} \mathrm{C}$ on sucrose containing medium. ${ }^{2}$ Anderson et al. reported an efficient carbohydrate fermenting Kluyveromyces marxianus var. marxianus producing $6 \% \mathrm{w} / \mathrm{v}$ ethanol at $43^{\circ} \mathrm{C}$ in 24 h. ${ }^{3}$ Two Saccharomyces and one Candida strains reported by Hacking et al. were found to meet minimum commercial targets set at $8 \%(\mathrm{v} / \mathrm{v})$ ethanol from $14 \% \mathrm{w} / \mathrm{v}$ glucose at $40^{\circ} \mathrm{C} .{ }^{4}$ This paper describes some features of two thermotolerant ethanol producing Saccharomyces cerevisiae strains isolated from coconut sap.

\section{METHODS AND MATERIALS}

Isolation of high-temperature yeast: Enrichment cultures were prepared using $5 \mathrm{ml}$ samples of toddy in $45 \mathrm{ml}$ of $10 \%$ glucose and incubated at $40^{\circ} \mathrm{C}$ for $24 \mathrm{~h}$. Subsequently the enriched cultures were used to prepare a series of dilution. followed by plating $0.1 \mathrm{ml}$ of each dilution on Yeast extract - Peptone - Dextrose - agar (YPD) medium composed of $2 \%$ dextrose, $2 \%$ peptone, $1 \%$ yeast extract, $2 \%$ agar and complete synthetic medium which has a composition similar to the basal medium described. ${ }^{5}$ To both these media $50 \mathrm{ppm}$ of Streptomycin was added to inhibit bacterial growth. The plates were incubated at $40^{\circ} \mathrm{C}$ for $2-3$ days. Morphologically different colonies that appeared on plates were picked up and purified by streaking on fresh YPD plates.

Selection of yeast strains capable of fermenting at $40^{\circ} \mathrm{C}$ : Fermentation tests were carried out with each of the strains isolated using broth cultures. First a seed culture was prepared using YPD broth at $30^{\circ} \mathrm{C}$ and the cell concentration of each of these cultures was monitored using a haemocytometer. For the fermentation test, $50 \mathrm{ml}$ amounts of YPD medium containing $15 \%(\mathrm{w} / \mathrm{v})$ glucose were dispensed in 250-ml capacity Erlenmeyer flasks fitted with fermentation bungs. The fermentation bungs were filled with concentrated sulphuric acid, which permitted only carbon dioxide to evolve from the culture. Water vapour and vaporized 
ethanol were trapped in the sulphuric acid. The flasks were inoculated with a known amount of cells $\left(1 \times 10^{8}\right.$ cells $\left.\mathrm{ml}^{-1}\right)$, from the seed culture of each of the isolates and were weighed after inoculation and then incubated statically at $40^{\circ} \mathrm{C}$ for $72 \mathrm{~h}$. The fermentation was monitored by measuring the daily carbon dioxide output as reflected by decrease in the weight of the whole culture. Twice the weight of carbon dioxide evolved is equivalent to the amount of sugar consumed by each yeast strain used in fermentation. ${ }^{6}$ Amount of sugar used up by each of the strains in fermentation was calculated and those strains that used up 50\% or more of the initial sugar content were selected for further studies.

Fermentation tests were again done using Yeast extract - Peptone - Sucrose (YPS) medium and synthetic medium containing $20 \%(\mathrm{w} / \mathrm{v})$ sucrose, at $40^{\circ} \mathrm{C}$, to check the fermentation ability of the selected yeast strains with sucrose as the carbon source. For comparison, baker's yeast was also used in these experiments. The amount of carbon dioxide evolved $(\mathrm{g})$ and the final ethanol concentration (\% $\mathrm{v} / \mathrm{v}$ ) of the fermenting mash were measured. The final ethanol concentration was measured using an ebulliometer.

Methods of identification: For taxonomical identification of yeast, the methods described $^{5.7}$ were followed.

Growth at different temperatures: The selected strains were tested for their ability to grow at different temperatures such as $40,45,47$ and $50^{\circ} \mathrm{C}$ in YPD agar medium. In complete synthetic liquid medium, the growth rates of the selected strains at $40^{\circ} \mathrm{C}$ were compared with Baker's yeast by measuring the optical density at $660 \mathrm{~nm}$, at intervals and then converted to cell density using a calibration curve.

Fermentation characteristics of selected yeast at different temperatures: Fermentation tests were carried out with the selected strains and Baker's yeast at different temperatures, 25,30 and $40^{\circ} \mathrm{C}$. As $40^{\circ} \mathrm{C}$ was found to be the optimum growth temperature of the yeast, it was selected to be the maximum temperature limit for fermentation. In both YPS and complete synthetic medium $20 \%(\mathrm{w} / \mathrm{v})$ sucrose was used. The carbon dioxide evolution rate and final ethanol concentration were determined as described earlier.

Fermentation using molasses medium: Molasses was diluted three folds to give approximately $20 \%$ fermentable sugars and potassium phosphate $(0.05 \%)$ and magnesium sulphate $(0.5 \%)^{s}$ were added. Before autoclaving, the $\mathrm{pH}$ was adjusted to 4.8 . Fermentation was carried out at 30 and $40^{\circ} \mathrm{C}$. The amount of carbon dioxide evolved and the ethanol concentrations (\% v/v) were determined as described earlier. 
Selecting the bestyeast strain for industrial alcohol production: For this purpose, the parameters, maximum productivity (based on carbon dioxide evolution), final alcohol concentration, ethanol yield ratio and maximum growth rate were used. Ethanol yield ratio was computed by dividing the actual ethanol yield by theoretical ethanol yield on the basis of Gay-Lussac equation (i.e. $0.511 \mathrm{~g}$ ethanol $\mathrm{g}^{-1}$ glucose, fructose or sucrose). The maximum growth rate was calculated from the exponential phase of the growth curve. Optical density was measured using a spectrophotometer at $660 \mathrm{~nm}$ and then converted to cell density using a calibration curve. Higher values for final ethanol concentration, carbon dioxide evolution rate and ethanol yield ratio have a positive influence on alcohol productivity while higher values for growth rate have a negative influence on alcohol productivity. ${ }^{9}$

\section{RESULTS}

Colonies, which had different morphology on dilution plates, were picked up and purified by streaking on fresh YPD plates. Fifteen stock cultures were prepared using YPD medium. Code numbers identified these.

In the fermentation experiments the loss in weight of the whole culture reflected the carbon dioxide productivity and twice that value indicated the amount of sugar consumed by the cell to produce alcohol according to Gay Lussac equation. Six strains capable of fermenting more than $50 \%$ of initial sucrose at $40^{\circ} \mathrm{C}$ were selected from the stock culture by preliminary fermentation tests. Out of the six strains, only two strains (SK-33 and T-31) gave high alcohol yield at $4.0^{\circ} \mathrm{C}$ with sucrose as the carbon source (Table 1 ).

Table 1: Fermentation screen of different strains of yeast at $40^{\circ} \mathrm{C}$ in YPS medium with $15 \%(w / v)$ sucrose.

\begin{tabular}{lccc}
\hline Strain No. & $\begin{array}{c}\text { Carbon dioxide } \\
\text { output g/100 ml }\end{array}$ & $\begin{array}{c}\text { Sucrose } \\
\text { consumed }(\mathrm{g})\end{array}$ & $\begin{array}{c}\text { Alcohol } \\
\% \mathrm{v} / \mathrm{v}\end{array}$ \\
\hline SK- 41 & 3.5 & 7.0 & 4.4 \\
SK- 33 & 5.5 & 11.0 & 6.9 \\
KT- 45 & 3.9 & 7.8 & 4.9 \\
T-31 & 5.3 & 10.6 & 6.6 \\
KT- 34 & 4.0 & 8.0 & 5.0 \\
TO- 44 & 3.5 & 7.0 & 4.5 \\
Baker's yeast & 5.2 & 10.4 & 6.2 \\
\hline
\end{tabular}


The two strains, T-31 and SK-33 thus selected agreed well with the standard description for Saccharomyces cerevisiae (Tables 2 and 3). Full DNA finger printing analysis of the above two cultures showed that they are significantly different from other brewing strains held in the National Collection of Yeast Cultures (NCYC) at Norwich, UK. Therefore, the above cultures, T-31 \& SK-33 were accessioned into NCYC after assigning the numbers NCYC 2401 and 2402 respectively.

Table 2: Morphological characters of yeast strains T-31 and SK -33.

Morphology on YM medium

Broth

Cells after $48 \mathrm{~h}$

Culture after $21 \mathrm{~d}$

Agar

Cells after $48 \mathrm{~h}$

Culture after $21 \mathrm{~d}$

Cream white, smooth slightly shiny
Strain SK-33

Oval $(3-7) \times(4 \times 8) \mu$

Cream non-flocculant deposit

Round to long oval $(4-6) \times(5-8) \mu$

Cream white slightly shiny

\section{Pseudo/true mycelium}

CMA Aerobic

PDA

Anaerobic

Aerobic

Anaerobic

Balistospores

Arthrospores

Endospores

Chlamydospores

Sexual spores

CMA

KAC \& Gorodkowa
No mycelium

No mycelium

No mycelium

No mycelium

Negative

Negative

Negative

Negative

Negative

4 ascospores/ascus Round-oval
Well developed

No mycelium

Poorly developed

No mycelium

Negative

Negative

Negative

Negative

\section{Negative}

3-4 ascospores/ascus Round

YM - Malt Extract, Yeast extract; PDA - Potato Dextrose agar; CMA - Com meal agar: KAC potassium acetate agar. 
Table 3: Physiological characters of the two yeast strains T-31 and SK -33.

T-31

$\mathrm{SK}-33$

\begin{tabular}{|c|c|c|c|c|}
\hline & Ferment. & Assimi. & Ferment. & Assimi. \\
\hline D-Glucose & + & + & + & + \\
\hline D-Galactose & + & + & + & + \\
\hline Sucrose & + & + & + & + \\
\hline Maltose & - & - & - & - \\
\hline Cellobiose & - & - & - & - \\
\hline Trehalose & - & $+(s)$ & - & $-(\mathrm{s})$ \\
\hline Lactose & - & - & - & - \\
\hline Melibiose & - & - & - & - \\
\hline Raffinose & + & + & + & + \\
\hline Melzitose & - & - & - & - \\
\hline \multicolumn{5}{|l|}{ Methyl-D } \\
\hline glucopyranoside & + & + & + & + \\
\hline Inulin & - & - & - & - \\
\hline Sol. Starch & - & - & - & - \\
\hline Xylose & - & - & - & - \\
\hline L-Arabinose & - & - & - & - \\
\hline D-Arabinose & - & - & - & - \\
\hline D-Ribose & - & - & - & - \\
\hline L-Rhamnose & - & - & - & - \\
\hline Ethanol & - & + & - & + \\
\hline
\end{tabular}


Table 3 contd.

T-31

Assimil.

Glycerol

Erythritol

Ribitol

Galcitol

D-Mannitol

Glucitol

Salicilin

Lactic acid

Succinic acid

Citric acid

Myo-inositol

D-Glucono

1,5 lactone

D-Glucosamine

Methanol

Xylitol

Ammonium sulphate

Potassium nitrate

Ethyl amine

Cadaverine

L-Lysine
SK-33

Assimil. 
Table 3 contd.

\begin{tabular}{lcc}
\hline & $\mathrm{T}-31$ & $\mathrm{SK}-33$ \\
\hline $\begin{array}{l}\text { Vitamin free growth } \\
\text { Cycloheximide } \\
\quad(0.01 \% \text { and } 0.1 \%)\end{array}$ & - & - \\
$\begin{array}{l}\text { Acetic acid } \\
\text { Acid production }\end{array}$ & - & - \\
Growth at $40^{\circ} \mathrm{C}$ & $\mathrm{w}$ & $\mathrm{w}$ \\
Arbutin hydrolysis & - & - \\
Urease activity & - & - \\
Salt tolerant $10 \%$ & - & - \\
\hline
\end{tabular}

$$
\mathrm{s}=\text { slow } \quad \mathrm{w}=\text { weak }
$$

Growth at different temperatures: The maximum growth temperature of these two yeasts was $45^{\circ} \mathrm{C}$. Both grew very well at $40^{\circ} \mathrm{C}$ (Table 4 ). No growth was observed at $47^{\circ} \mathrm{C}$ and $50^{\circ} \mathrm{C}$. The growth rate of SK-33 in synthetic medium was higher while T-31 and Baker's yeast had a lower growth rate. The yeasts appear thermotolerant.

Table 4: Growth characteristics of selected yeast strains at different temperatures in YPD medium.

\begin{tabular}{lcccc}
\hline Strain & $40^{\circ} \mathrm{C}$ & $45^{\circ} \mathrm{C}$ & $47^{\circ} \mathrm{C}$ & $50^{\circ} \mathrm{C}$ \\
\hline $\mathrm{T}-31$ & +++ & ++ & - & - \\
SK-33 & +++ & ++ & - & - \\
Baker's & +++ & + & - & - \\
yeast & & & & \\
\hline
\end{tabular}

+++ very good, ++ good, + weak, - No growth 
Alcohol fermentation at different temperatures: In fermentation tests at $30^{\circ} \mathrm{C}$ in YPS medium, SK-33 and T-31 gave more than $12 \% \mathrm{v} / \mathrm{v}$ alcohol, whereas Baker's yeast gave less alcohol $11.7 \% \mathrm{v} / \mathrm{v}$. At $40^{\circ} \mathrm{C}$ in the same medium, strain $\mathrm{T}-31$ performed better, giving an alcohol concentration around $7.4 \% \mathrm{v} / \mathrm{v}$ (Fig. 1). With increase of temperature from 30 to $40^{\circ} \mathrm{C}$, the alcohol concentration obtained with this strain decreased by about $41 \%$. In the synthetic medium with $20 \%$ sucrose at $30^{\circ} \mathrm{C}$ all strains gave higher alcohol concentration, more than $10 \% \mathrm{v} / \mathrm{v}$ and $\mathrm{SK}-33$ gave highest concentration, $13.2 \% \mathrm{v} / \mathrm{v}$. At $40^{\circ} \mathrm{C}$ also, the concentrations were higher in this medium with strain SK-33 giving the highest value $(8.4 \% \mathrm{v} / \mathrm{v}$, Fig. 2). In the synthetic medium with increase of temperature the $\%$ decrease in alcohol concentration was about $36 \%$. The 'balance sheet' (Table 5) with respect to fate of sugar and production of ethanol in the two media at $40^{\circ} \mathrm{C}$ shows that the difference between the observed and calculated values for ethanol is very small. This confirmed that there is no great loss of ethanol due to evaporation at high temperature.

Table 5: 'Balance Sheet' regarding fate of sugar and production of ethanol in YPS and synthetic media at $40^{\circ} \mathrm{C}$.

\begin{tabular}{|c|c|c|c|}
\hline Strain & $\begin{array}{l}\text { Amount of sugar } \\
\text { used up (g) }\end{array}$ & $\begin{array}{c}\% \text { Alcohol } \\
\text { (Theoretical) (v/v) }\end{array}$ & $\begin{array}{c}\% \text { Alcohol } \\
(\text { Actual })(\mathrm{v} / \mathrm{v})\end{array}$ \\
\hline
\end{tabular}

Medium - YPS

$\begin{array}{lccc}\text { T }-31 & 12.04 & 7.68 & 7.4 \\ \text { SK -33 } & 10.61 & 6.76 & 6.7 \\ \text { Baker's } & 11.02 & 7.03 & 6.8 \\ \text { yeast } & & & \end{array}$

Medium - Synthetic

$\begin{array}{lrrr}\text { T }-31 & 13.07 & 8.33 & 8.2 \\ \text { SK - 33 } & 13.27 & 8.46 & 8.4 \\ \text { Baker's } & 12.65 & 8.06 & 8.0 \\ \text { yeast } & & & \end{array}$

YPS - Yeast extract, Peptone, Sucrose medium. 


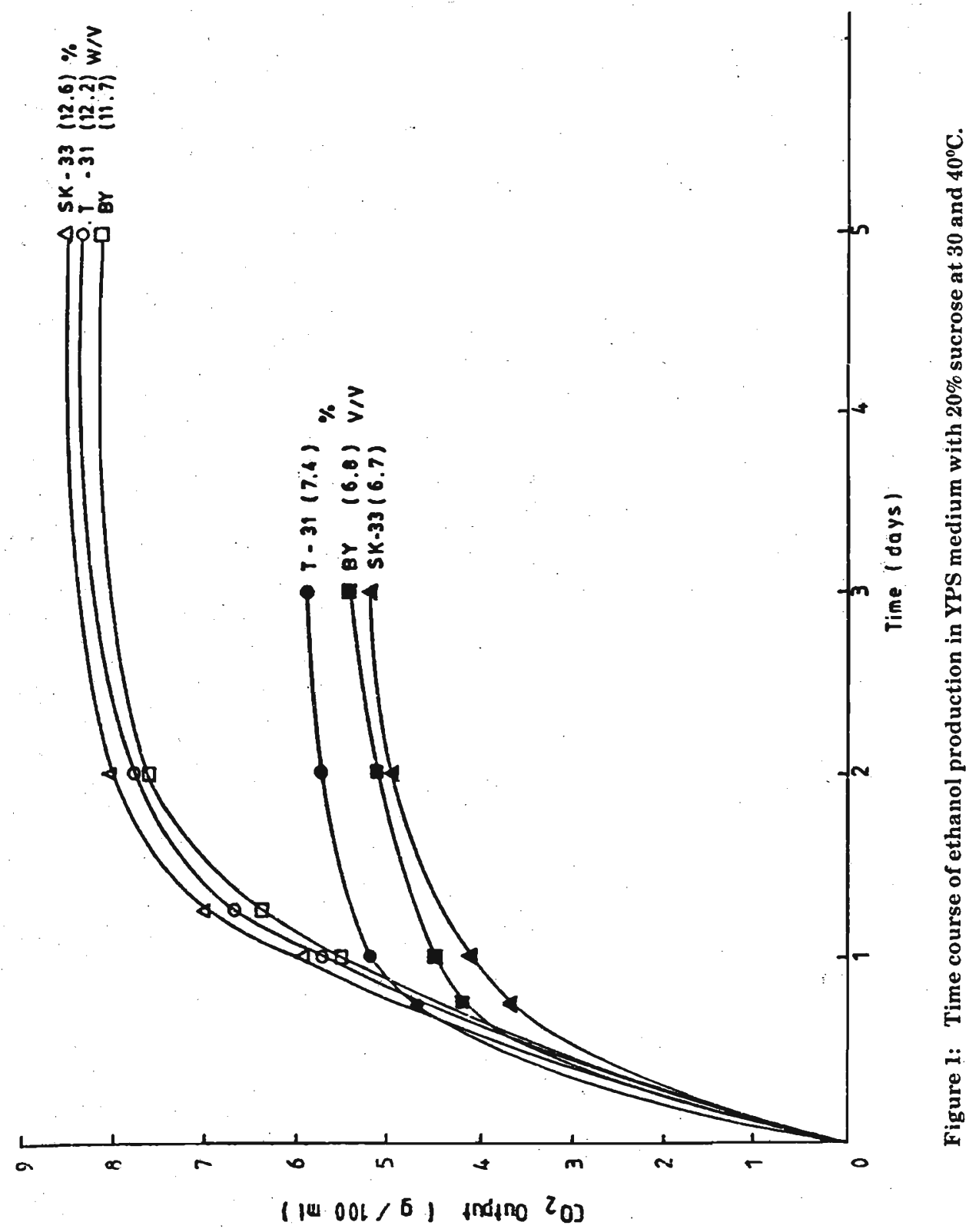




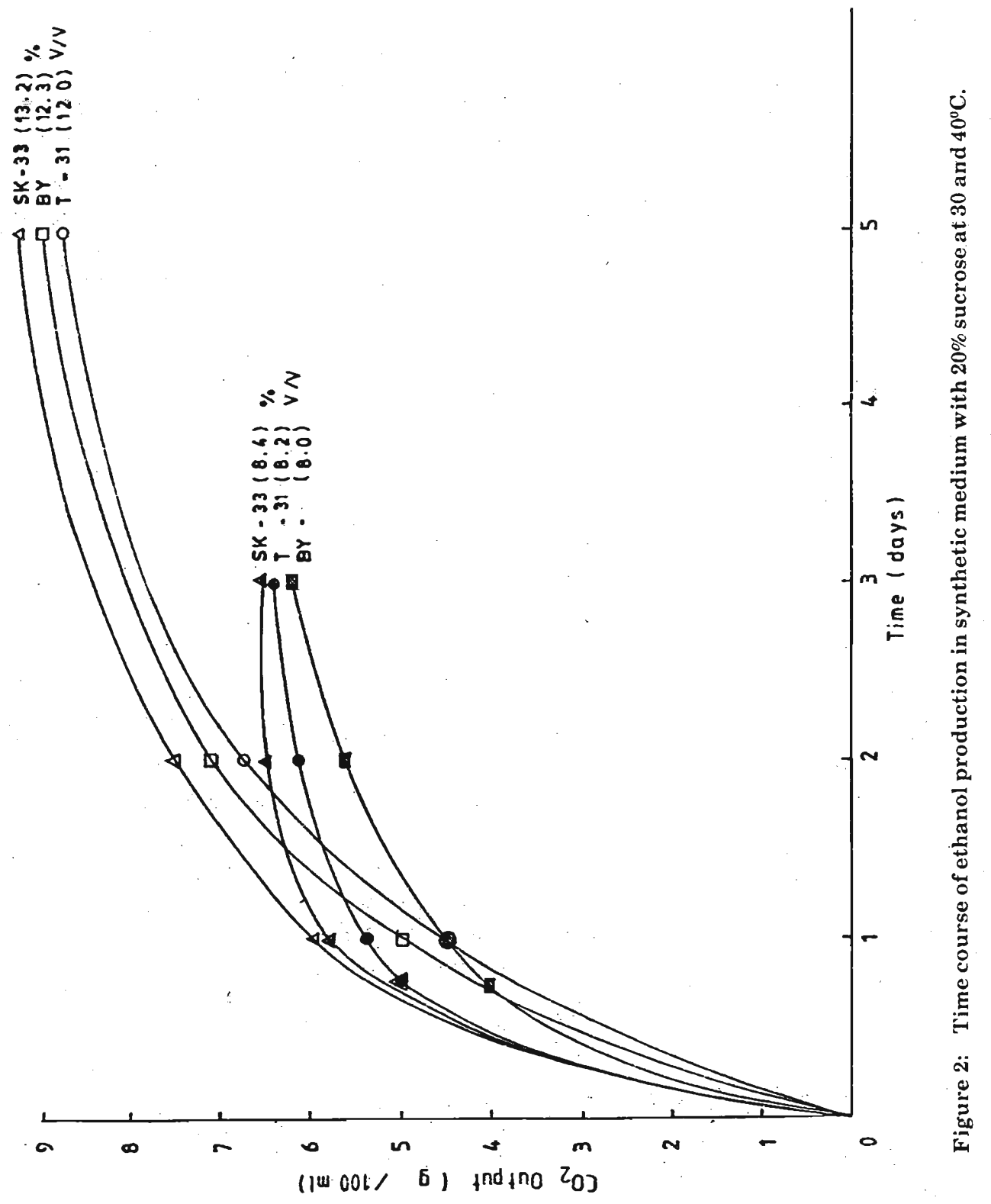


Alcohol fermentation using molasses: In the molasses medium at 30 and at $40^{\circ} \mathrm{C}$, T-31 gave highest alcohol concentration of $11.9 \% \mathrm{v} / \mathrm{v}$ and $5.4 \% \mathrm{v} / \mathrm{v}$ respectively (Fig. 3). Baker's yeast in the same medium produced lower alcohol concentrations, $11.5 \%, 4.7 \%$ at 30 and $40^{\circ} \mathrm{C}$ respectively. The percentage decrease in the alcohol yield with increase of temperature, was less in the case of $T-31$ (54\%) than in Baker's yeast (59\%).

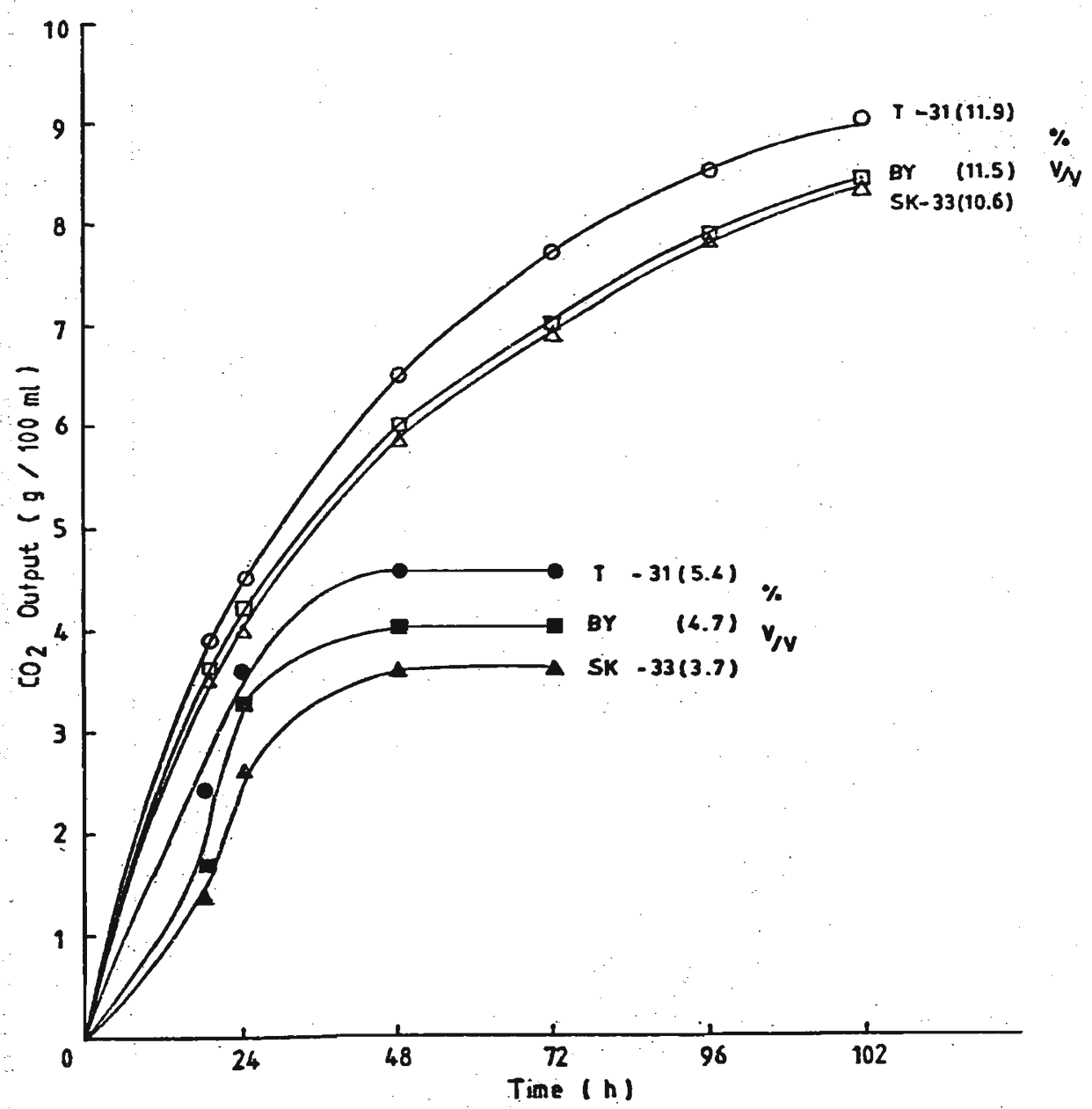

Figure 3: Time course of ethanol production in molasses medium at 30 and $40^{\circ} \mathrm{C}$. 
The values obtained for different parameters that were used in the selection of a suitable strain for industrial alcohol production are shown in Table 6 . In strain T-31, all parameters that have a positive influence on alcohol production (i.e. $\mathrm{CO}_{2}$ productivity, final ethanol concentration and ethanol yield ratio) gave higher values. Further, the same strain gave a lower value for maximum growth rate $(0.029)$, which has a negative influence on alcohol production.

Table 6: Comparison of criteria used in evaluation of fermentation performance of selected yeast strains with Baker's yeast at $40^{\circ} \mathrm{C}$ in YPS medium.

\begin{tabular}{lcccc}
\hline Strain & $\begin{array}{l}\text { Maximum carbon } \\
\text { dioxide productivity } \\
\left(\mathrm{gh}^{-1}\right)\end{array}$ & $\begin{array}{l}\text { Final ethanol } \\
\text { conc. (v/v) }\end{array}$ & $\begin{array}{l}\text { Ethanol yield } \\
\text { efficiency }\end{array}$ & $\begin{array}{l}\text { Growth } \\
\text { rate } \\
\left.\text { (cells } \mathrm{ml}^{-1} \mathrm{~h}^{-1}\right)\end{array}$ \\
\hline $\mathrm{T}-31$ & 0.216 & 7.4 & 0.579 & 0.029 \\
$\mathrm{SK}-33$ & 0.179 & 6.7 & 0.524 & 0.110 \\
$\begin{array}{l}\text { Baker 's } \\
\text { yeast }\end{array}$ & 0.187 & 6.8 & 0.532 & 0.032 \\
\hline
\end{tabular}

Yield efficiency $=$ Actual yield/Theoretical yield $=$ Actual yield/0.511

\section{DISCUSSION}

Although several reports are available on the flora of fermenting coconut palm wine, no studies have been done on thermotolerant yeast strains. Temperature is a paramount important regulatory factor in alcohol fermentation, particularly in tropical countries. There are a number of studies on the thermotolerance of growth and fermentation of different yeast strains. However this is the first instance that apparently thermotolerant yeasts have been isolated from coconut toddy. The strain (T-31) Saccharomyces cerevisiae (NCYC 2401), isolated from coconut toddy gave $7.4 \% \mathrm{v} / \mathrm{v}$ alcohol within 24 to $36 \mathrm{~h}$, in YPS medium, but the initial sugar concentration was higher $20 \% \mathrm{w} / \mathrm{v}$. Two Saccharomyces and one Candida have been found to meet minimum commercial targets set at $8 \%(\mathrm{v} / \mathrm{v})$ ethanol from $14 \% \mathrm{w} / \mathrm{v}$ glucose at $40^{\circ} \mathrm{C} .{ }^{4}$ There have been several studies on the thermotolerance of growth and fermentation of $S$. cerevisiae and $S$. uvarum strains and some results are contradictory. In general, the conclusion is that higher the fermentation temperature greater the inhibitory effect of ethanol on cells. ${ }^{10,11}$ Some have reported increase in ethanol tolerance with increase of temperature. ${ }^{12}$ It has also been reported that growth and fermentation can be lost in the range of $35-45^{\circ} \mathrm{C} .{ }^{13}$ In this study, at $40^{\circ} \mathrm{C}$ Saccharomyces cerevisiae (NCYC 2401) gave 7.4\% and $5.4 \% \mathrm{v} / \mathrm{v}$ alcohol in YPS and molasses media respectively. When alcohol yields at high temperatures are compared with those 
at lower temperatures, both these yeasts were found to give higher alcohol yields at low temperatures in all media tested. This decrease in alcohol yield at higher temperature could be due to the damaging effect of temperature on yeast cells. However, the results indicate that the yeast strains isolated from coconut toddy have the potential to produce high alcohol yields at fairly high temperatures and would be suitable to be used in molasses fermentation even without a sophisticated cooling system.

\section{Acknowledgements}

This work was supported by a grant (RG/90/B/2) from the Natural Resources, Energy and Science Authority. The assistance of the National Collection of Yeast Cultures in identifying of yeast cultures is gratefully acknowledged.

\section{References}

1. Dharmawardene M.W.N. (1986). Report of the present status of the utilisation of molasses and the by product of fermentation and recommendations on ways of better utilisation of these products. Sugar Cane Research Institute, Sri Lanka, 1-20.

2. Fleming M., Barron N., McHale L., Marchant R. \& McHale A.P. (1993). Studies on the growth of a thermotolerant yeast strain, Kluyveromyces marxianus IMB3 on sucrose containing media. Biotechnology Letters 15 : 1195-1198.

3. Anderson J., McNeil K. \& Watson K. (1986). High-efficiency carbohydrate fermentation to ethanol at temperatures above $40^{\circ} \mathrm{C}$ by Kluyveromyces marxianus var. marxianus isolated from sugar mills. Applied and Environmental Microbiology 51: 1314-1320.

4. Hacking A.J., Taylor I.W.F. \& Hanas C.M. (1984). Selection of yeast able to produce ethanol from glucose at $40^{\circ} \mathrm{C}$. Applied Microbiology and Biotechnology 19: 361-363.

5. Lodder J. (1984). "The Yeast" A taxonomic study. 3rd. ed. pp. 1385. North Holland Publishing Company. Amsterdam.

6. Flor P. Q. \& Hayashida S. (1983). Saccharomyces uvarum inulyticus var. nov. a new high-concentration ethanol tolerant yeast from rice wine. European Journal of Applied Microbiology 8: 148-152. 
7. Barnett J. A., Payne R.W. \& Yarrow D. (1979). A guide to identifying and classifying yeast. pp. 315, Cambridge University Press. London.

8. Tammarate P., Takada N. \& Oshima Y. (1981). Taxonomy study on yeast isolated from Thai coconut sap and Loog Pang and selection of strains for alcoholic fermentation. Annual Reports of ICME 5: 315-331.

9. Lin J.J., Dale M.C. \& Okos M.R. (1990). Ethanol production by Zymomonas mobilis in an Immobilised Cell Reactor Separator. Process Biochemistry 25: 61-66.

10. Nagodawithana T.W., Castellano C. \& Steinkraus K.H. (1974). Effect of dissolved oxygen, temperature, initial cell count and sugar concentration on the viability of Saccharomyces cerevisiae in rapid fermentation. Applied Microbiology 28: 383-391.

11. Jones R.P., Pamment N. \& Greenfield P.F. (1981). Alcohol fermentation by yeast - the effect of environment and other variables. Process Biochemistry 16: $42-49$.

12. Brown S.W. \& Oliver S.G. (1982). The effect of temperature on the ethanol tolerance of the yeast Saccharomyces uvarm. Biotechnology Letters 4: $269-274$.

13. Krouwel P.G. \& Barber L. (1979). Ethanol production by yeast at supraoptimal temperature. Biotechnology Letters 1: 403-408. 